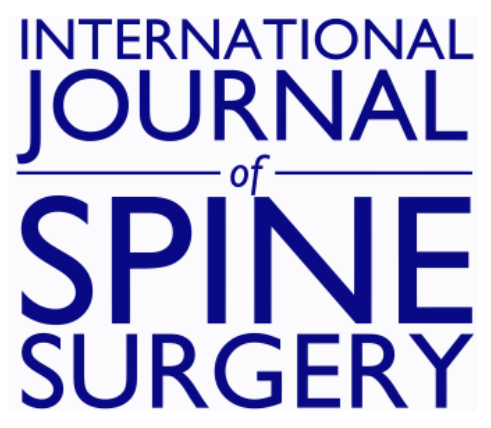

\title{
Lateral Pressure and VAS Pain Score Analysis for the Lateral Lumbar Interbody Fusion Procedure
}

Robert Louis Tatsumi

Int J Spine Surg 2015, 9 ()

doi: https://doi.org/10.14444/2048

http://ijssurgery.com/content/9/48

This information is current as of April 26, 2023.

Email Alerts Receive free email-alerts when new articles cite this article. Sign up at:

http://ijssurgery.com/alerts

The International Journal of Soine Surgerh 2397 Waterbury Circle, Suite 1,

Aurora, IL 60504, Phone: +1-630-375-1432

(C) 2015 ISASS. All Rights Reserved. 


\section{Lateral Pressure and VAS Pain Score Analysis for the Lateral Lumbar Interbody Fusion Procedure}

Robert Louis Tatsumi, MD

Northwest Spine Research Foundation, Tualatin, OR

\section{Abstract}

Background

The lateral lumbar interbody fusion (LLIF) procedure is a minimally invasive procedure that has become widely utilized. The LLIF procedure typically involves bending the table to access the disc spaces of interest due to anatomical constraints. It is unknown if this bending process is painful or what pressures are exhibited on the downside part of the body. The goal of the study was to determine whether sex, height, weight, body mass index, bed angle, or positioning relative to the break of the bed affects the downside skin pressures and VAS pain scores in awake volunteers.

\section{Methods}

Fifty-six volunteers were placed in the lateral decubitus position and pressure sensors were placed at the downside part of their anatomy (shoulder, T10 rib, iliac crest, and greater trochanter). The pressures were checked with the iliac crest or greater trochanter at $0,10,20,30,40$ degree bed angles. VAS scores were checked when the iliac crest or greater trochanter were at the maximum bed break angles.

Results

A significant positive association was found between increased bed angle and pressure at all five areas on the downside body locations $(\mathrm{p}<0.0001)$. The greatest pressures were located at the iliac crest and greater trochanter when these specific locations were centered over the break of the bed $(\mathrm{p}<0.0001)$. When the iliac crest was placed at maximal bed break, each unit increase in BMI increased the VAS pain by $0.13(\mathrm{p}<0.0001)$ and men had 1.96 $(\mathrm{p}=0.0009)$ higher VAS scores then women. When the greater trochanter was placed at the maximal bed break, each unit increase in BMI decreased VAS pain by $0.19(\mathrm{p}<0.0001)$ and women had $1.55(\mathrm{p}=0.0002)$ higher VAS pain scores then men.

\section{Conclusions}

In awake volunteers, the pressure at the iliac crest or greater trochanter at the break of the bed increases by increasing the bed angle. Women with a lower BMI had high VAS pain scores when their greater trochanter was at maximal bed break. Men with higher BMI had high VAS pain scores when their iliac crest was at maximal bed break. An awareness of the iliac crest or greater trochanter at the break of the bed should be considered to prevent pain and increased pressure based on the patient's sex and BMI.

KEYWORDS: LATERAL LUMBAR INTERBODY FUSION, LUMBAR SURGERY COMPLICATIONS, LUMBAR PRESSURE ANALYSIS, LUMBAR VISUAL ANALOG PAIN SCORES

VOLUME 9 ARTICLE 48 DOI: $10.14444 / 2048$

\section{Introduction}

Lateral lumbar interbody fusion (LLIF) procedures have become an increasingly popular surgical technique due to the benefits of minimal tissue disruption, excellent disc visualization, ability to insert a large intervertebral cage to lessen subsidence, and faster recovery times. ${ }^{1-2}$ The LLIF procedure differs from other lumbar procedures in that the patient is Downloaded from http://ijssurgery.com/ by guest on April 26, 2023 positioned in the lateral decubitus position, often times utilizing bending the bed near the iliac crest region in order to facilitate access to the L4-5 disc space.

The complication rate during the LLIF procedure has been reported to range from $2 \%$ to $30 \%$ with up to $20 \%$ minor and $8.6 \%$ major complications..$^{3-5}$ One type of minor complication that can be experienced is re- 
lated to skin abrasion from tape as the patient is secured to the bed. Surgeons typically tape bony prominences by applying foam pads on the skin but not over truncal regions. Since the patient is asleep for the taping procedure, there is no knowledge about how much pressure applied to the skin can cause pain. A second minor complication is the incidence of pain mimicking that of trochanteric bursitis presumably due to direct pressure of the greater trochanter against the table.

A major complication with LLIF is rhabdomyolysis or muscle necrosis due to prolonged soft tissue pressure which can lead to acute renal failure. ${ }^{6}$ Rhabodmyolsis can be diagnosed by rising creatine phosphokinase levels and must be quickly identified to initiate appropriate medical treatment.

The goals of this study were to evaluate the amount of tape pressure that causes pain or discomfort during the surgical positioning, quantify the pressure points on the dependent side of the body as the bed angle increases, and understand if pain varies by body position in respect to the break of the bed and/ or due to bed angle.

\section{Materials and Methods}

A prospective cohort of 56 conscious volunteers were evaluated for pain and pressure on the dependent side of the body while in the lateral decubitus position. The study was conducted at two hospitals and informed consent was obtained.

Age, sex, height, weight, and BMI were recorded for each subject. Subjects were clothed in scrubs and then placed in a lateral decubitus position on a Mizuhosi table (Cunion City, CA) with the hips and knees flexed at 45 degrees. Pressure Profile System Sensors (Los Angeles, CA) were placed on the dependent at the shoulder, T10 rib, iliac crest, and greater trochanter.

Four inch Kendall hypoallergenic cloth tape (Mansfield, MA) attached to a digital hanging scale (LED American Weigh Norcross, GA) was used. The tape was then applied circumferentially around the bed/ chest and bed/greater trochanter regions twice. The volunteers were asked to respond when they began to experience pain or discomfort and this pressure was then documented.

The taping procedure was performed with the iliac crest and greater trochanter at the bed break. Dependent side pressure measurements were then recorded for both respective bed break positions with the break angle at 0 degrees, 10 degrees, 20 degrees, 30 degrees and then 40 degrees. The bed position remained at each angular increase for about 30 seconds while the pressure sensors were recorded.

All volunteers were asked to rate their pain on the $\mathrm{Vi}$ sual Analog Scale at the highest bed break angle that they could tolerate.

\section{Statistical Methods}

In regards to measuring the pressure points on the body, the bed angle was treated as a continuous variable. Linear mixed models with a random intercept for each subject were used to account for the correlation due to repeated measures.

\section{Results}

There were 36 females and 20 male volunteers. The average age was (37.5) years old. The average height was $168.08 \mathrm{~cm}$, the average weight was $72.62 \mathrm{~kg}$, and the average BMI was $25.59 \mathrm{~kg} / \mathrm{m}^{2}$.

The average tape pressure that was recorded as uncomfortable but tolerable was 9.2 pounds with a standard deviation of 1.2. There was no evidence of tape abrasion or bruising on any subjects.

Shoulder pressure demonstrated statistically significant effects of both the location at the bed break $(\mathrm{p}=0.013)$ and the angle of the bed $(\mathrm{p}=0.015)$. On average, when the bed break is at the iliac crest this resulted in pressures $0.1222 \mathrm{mPa}$ higher at the shoulder then when the bed break was at the greater trochanter (95\% CI: 0.08161 to 0.1629 ). For each 10 degree increase in angle, the pressure at the shoulder decreased by $0.02329 \mathrm{mPa}$ (95\%CI: -0.03766 to 0.00893). See Figure 1.

The tenth rib pressure did not show a statistically 
significant difference when the greater trochanter or iliac crest was at the bed break. $(\mathrm{p}=0.7487)$. The angle of the break did not make a statistically significant difference in pressure at the tenth rib $(\mathrm{p}=0.0138)$. For each 10 degree increase in angle, the pressure at the tenth rib decreased by $-0.01475 \mathrm{mPa}(95 \% \mathrm{CI}$ : -0.02647 to -0.00302$)$. See Figure 2.

Iliac crest pressure depends on the angle of the bed when the iliac crest is placed the bed break

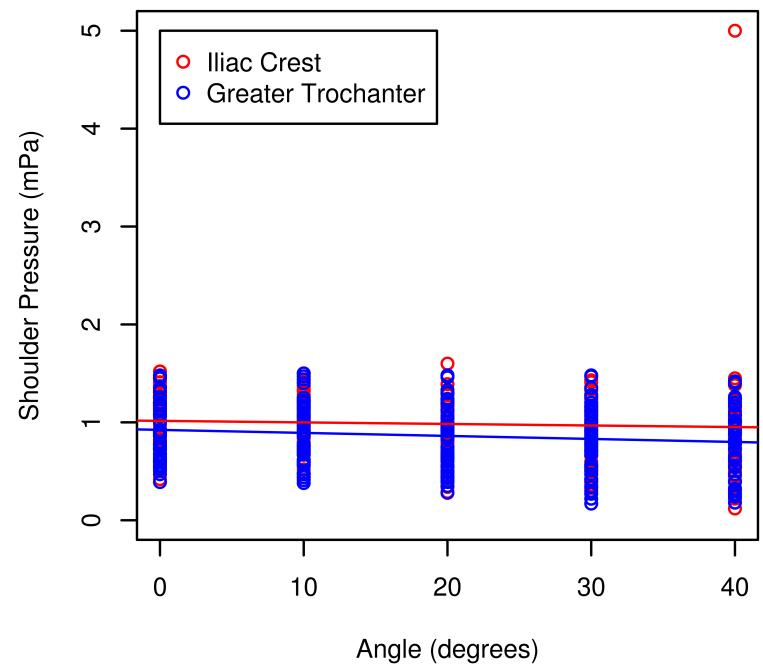

Fig. 1. Shoulder Pressure Versus Bed Angle.

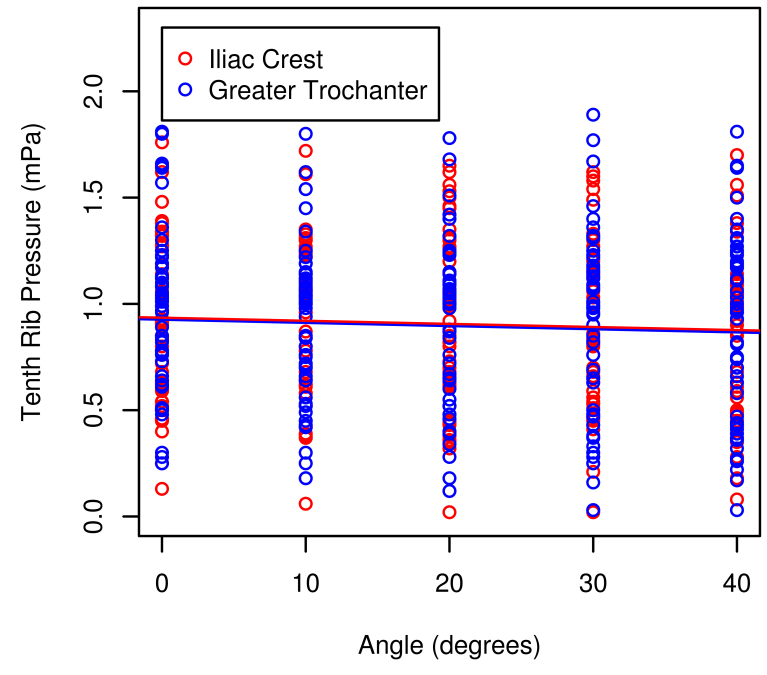

Fig. 2. Tenth Rib Pressure Versus Bed Angle. $(\mathrm{p}<0.0001)$. With the iliac crest placed at the bed break, the pressure increased $0.2369 \mathrm{mPa}(95 \% \mathrm{CI}$ : 0.1927 to 0.2812 ) for each 10 degree of angle increase. When the greater trochanter was placed at the bed break, the pressure at the iliac crest was not significantly influenced by the bed angle $(\mathrm{p}=0.8065)$. See Figure 3.

The greater trochanter pressure depends on the angle of the break $(p<0.0001)$. With the greater trochanter at the bed break, for each 10 degree angle increase, the pressure increases by $0.2615 \mathrm{mPa}(95 \%$ CI: 0.2090 to 0.3140 ). With the iliac crest positioned at the bed break, the pressure increases by 0.06887 $\mathrm{mPa}$ (95\% CI: 0.01637 to 0.1214 ) for each 10 degree increase in angle. At an angle of 20, the greater trochanter at the bed break results in 0.4241 more pressure than the iliac crest placed at the bed break(95\% CI: 0.3191 to 0.5291). See Figure 4.

One hundred percent of subjects recorded VAS values when the bed break was at 40 degrees. A simple linear regression model was run for each pressure point, modeling pressure as a function of VAS. No additional covariates were included in the model. Six subjects had a VAS score greater then 6 . This was too few of an event for a reliable logistic regression which would require 10 events per predictor variable. See Figure 5 and Figure 6.

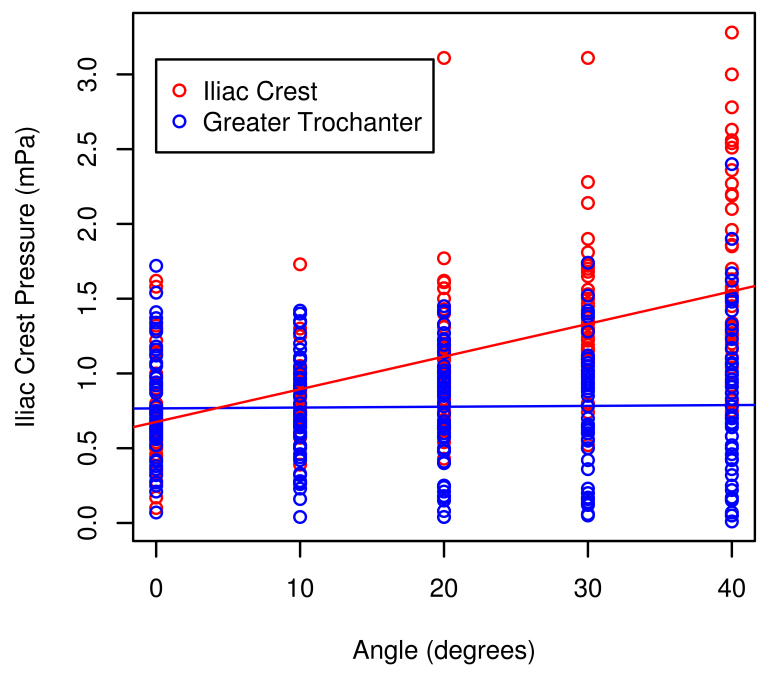

Fig. 3. Iliac Crest Pressure Versus Bed Angle. 
With 40 degrees of break angle at the iliac crest, sex, height, weight and BMI correlate significantly with VAS scores. For each 1 unit increase in BMI, VAS increases by $0.13(\mathrm{p}=0.0012)$ and women tend to have 10.9 lower VAS scores then males, controlling for BMI ( $<<0.001)$. Controlling for weight and sex, for each $1 \mathrm{~cm}$ increase in height, VAS decreases by 0.06 $(\mathrm{p}=0.0224)$. Controlling for height and sex, VAS increases by 0.05 for each $\mathrm{kg}$ of weight $(\mathrm{p}=0.0008)$. On average, women have -2.18 lower VAS scores then

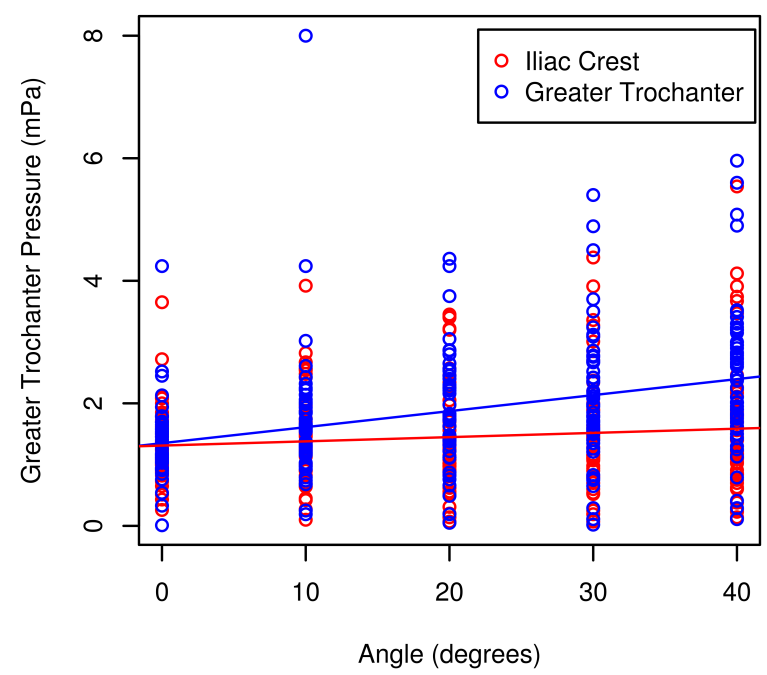

Fig. 4. Great Trochanter Pressure Versus Bed Angle.

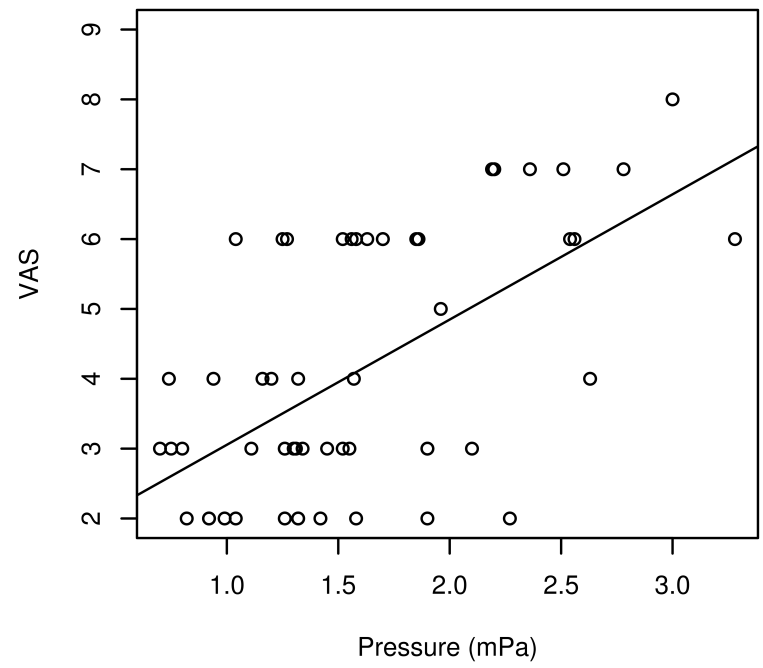

Fig. 5. VAS Versus Pressure (Break at lliac Crest). men, controlling for height and weight $(\mathrm{p}<0.0001)$. See Figure 7.

With 40 degrees of break angle at the greater trochanter, sex, height, weight and BMI correlate significantly with VAS scores. On average, controlling for BMI, women have a 1.55 higher VAS score then men $(p=0.002)$. For each 1 unit increase in BMI, pain decreases by 0.19 points $(\mathrm{p}<0.0001)$. Controlling for weight and sex, for each 1 unit increase in

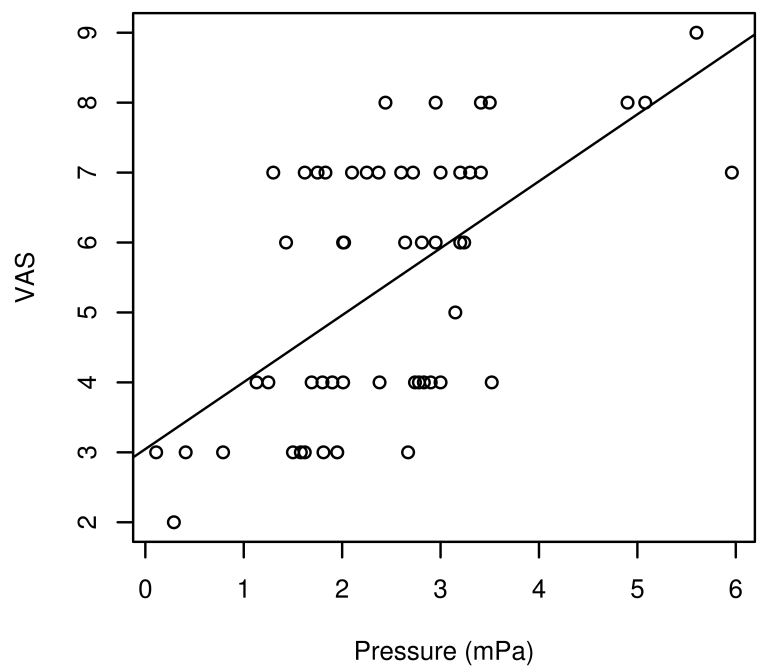

Fig. 6. VAS Versus Pressure (Break at Greater Trochanter).

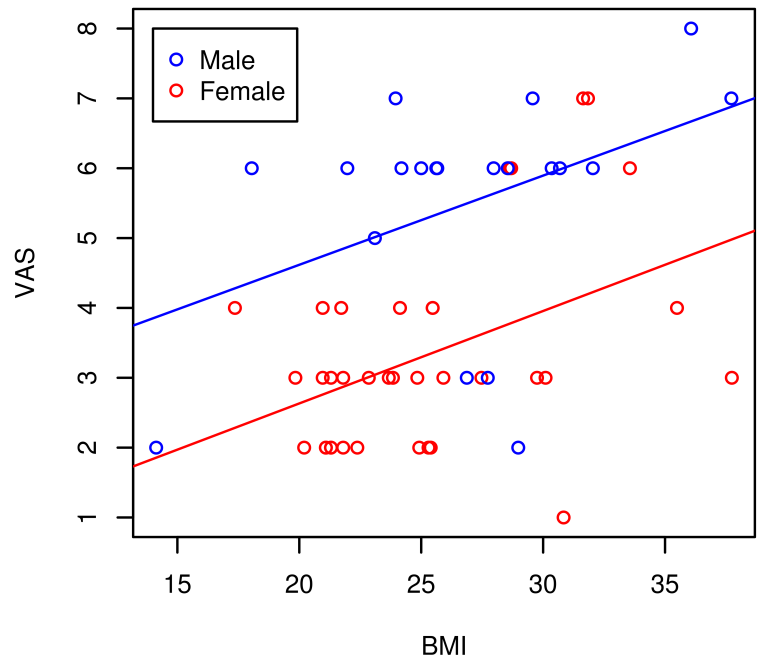

Fig. 7. VAS Versus BMI (Break at lliac Crest). 
height, VAS increases by $0.10(\mathrm{p}<0.0001)$. Controlling for height and sex, VAS decreases by 0.06 for each $\mathrm{kg}$ of weight $(\mathrm{p}<0.0001)$. On average, women have 2.27 higher VAS scores then men, controlling for height and weight $(\mathrm{p}<0.0001)$. See Figure 8.

\section{Discussion}

The LLIF procedure is a useful procedure for spinal surgeons. It is important, however, to better understand complications associated with this procedure whether it is at the non-dependent or dependent side of the body.

\section{Non-dependent side of the body}

This study demonstrated that the pressure applied while securing conscious subjects with tape can cause discomfort and pain. While there is no standardized tape tensioner available on the market, approximately 9 pounds or less of tension should be considered when securing the patient to the table to limit pain.

There are anecdotal reports of tape abrasion from this procedure. It is not surprising that this study did not demonstrate any tape related skin disruption since the subjects dictated how much pressure was applied to their skin.

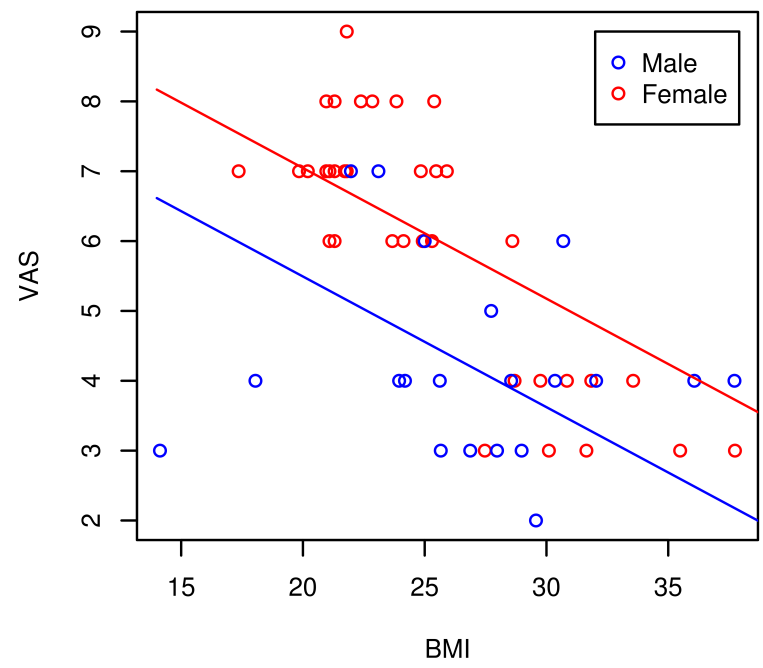

Fig. 8. VAS Versus BMI (Break at Greater Trochanter).
Dependent side of the body

Shoulder and tenth rib pressure on the dependent side decreased as break angle increased, regardless of if the iliac crest or greater trochanter was placed at the bed break. As the bed angle increases, the pressure transfers to the body region at the bed break.

The iliac crest pressure was the greatest when the iliac crest placed over the bed break and the greater trochanter pressure was the greatest when the greater trochanter was placed over the bed break. These findings make sense as these bony prominences are placed at the fulcrum and increasing the bed angle causes more weight to be distributed over a smaller surface area. It is probable that the reported causes of rhabdomyolysis stems from these areas and surgeons can prevent this devastating condition by reducing the bed angle promptly to a more neutral position when surgically appropriate.

In regards to VAS pain scores, subjects all had pain with bed break at 40 degrees. With the iliac crest at the bed break, males with a high BMI demonstrated increased VAS pain scores. With the greater trochanter at the bed break, females with a low BMI demonstrated increased VAS pain scores. Six patients had a VAS $>6$ which is important since the volunteers were in this specific position for less then 30 seconds.

There are limitations to this study. For the nondependent side of the body, the volunteers were taped while they were awak to identify what tension caused pain. In the operative setting, surgeons tape the patient to not only secure the torso to the bed but to also help migrate the iliac crest distally when trying to fluoroscopically visualize the L4-5 disc space. This study did not evaluate the tap tension necessary to image the disc space fluoroscopically. Femoral nerve injury can also occur and this may be due to increasing the bed angle or due to direct trauma during the LLIF procedure. This study did not evaluate potential causes for femoral nerve injury.

For the dependent side of the body, the amount of pressure can be underestimated due this setup. First, the volunteers dictated the tap tension and this could be les that what typically occurs in the operative set- 
ting. Second, the volunteers were placed at the bed break at each position for no greater than 5 minutes and not the typical duration for the LLIF procedure. Finally, trialing and hardware insertion also increases pressure on the dependent side of the body and this was not replicated during this study.

This study presents a better understanding of the pain associated with positioning the patient for the LLIF procedure. Securing the patient to the bed with tape causes pain. Increasing the bed angle to 40 degrees can cause considerable pain. Males with high BMI's had increased pain when the iliac crest was positioned at the bed break. Females with low BMI's had increased pain when the greater trochanter was positioned at the bed break. Continued attention to patient positioning is important to better understand how to achieve improved outcomes with the LLIF procedure.

\section{Acknowledgements}

Kim Martin for her statistical analysis and Ellie Raines for her assistance with volunteer coordination.

\section{References}

1. Rodgers WB, Gerber EJ. Outcomes of MIS spinal fusion: 12 and 24 months. The Spine Journal 2010: 10:9: S141.

2. Isaacs RE, Hyde J, Goodrich JA, et al. A prospective, nonrandomized, multicenter evaluation of ex- treme lateral interbody fusion of the treatment of adult degenerative scoliosis: perioperative outcomes and complications. Spine 2010: 15:35: S322-30. 3. Youssef JA, McAfee PC, Patty CA, et al. Minimally invasive surgery: lateral approach interbody fusion: results and review. Spine 2010:35:S302.

4. Rodgers WB, Gerber EJ, Patterson J. Intraoperative and early postoperative complications in extreme lateral interbody fusion: an analysis of 600 cases.

Spine 2011: 1:36: 26-32.

5. Smith WD, Christian GM, Serrano S. Neurologic complications in extreme lateral interbody fusion (XLIF): A comparative analysis of levels L2-3, L3-4, and L4-5. The Spine Journal 2012: 12:9:S124.

6. Dakwar E, Rifkin SI, Volcan IJ, et al. Rhabdomyolysis and acute renal failure following minimally invasive spine surgery. J Neurosurg Spine

2011;14:785-788.

\section{Disclosures}

The author reports no relevant financial disclosures.

\section{Corresponding Author}

Robert Tatsumi, Northwest Spine Research Foundation, 19255 SW 65th Ave. Suite 200, Tualatin, OR 97062 .

Published 28 September 2015.

This manuscript is generously published free of charge by ISASS, the International Society for the Advancement of Spine Surgery. Copyright @ 2015 ISASS. To see more or order reprints or permissions, see http://ijssurgery.com. 